\title{
Mathematical creativity and mathematical giftedness in the primary school age range: an interview study on creating figural patterns
}

\author{
Daniela Assmus $^{1} \cdot$ Torsten Fritzlar $^{1}$ (D) \\ Accepted: 3 January 2022 / Published online: 28 January 2022 \\ (c) The Author(s) 2022
}

\begin{abstract}
Relationships between mathematical giftedness and mathematical creativity have been widely studied, but few studies are available for primary school age. For an investigation in this age group, it seems appropriate to use a content area that not only has high relevance for mathematics and special potentials for creativity, but also requires only a little knowledge and is easily accessible. We therefore investigated whether mathematically gifted primary school students differ from non-gifted ones in high creativity in dealing with mathematical patterns and structures. This question was explored in an interview study in which 24 third graders were asked to invent as many different figural patterns as possible, which enabled creative mathematical activity also by combining arithmetic and geometric aspects. A detailed qualitative analysis of the data revealed among other results several types of flexibility concerning the invention of patterns. The selection of students ensured that all participants performed well to very well in regular mathematics classes and that 14 of them could additionally be assumed to be mathematically gifted based on a specific test. This allowed a comparison of both subgroups. Results indicate a high correspondence between mathematical giftedness and mathematical creativity concerning the invention of figural patterns.
\end{abstract}

Keywords Mathematical creativity $\cdot$ Mathematical giftedness $\cdot$ Figural patterns

\section{Introduction}

(Mathematical) giftedness and (mathematical) creativity are constructs that are often mentioned in the same breath and whose relationships have been repeatedly investigated. (For an overview of possible relationships see Assmus \& Fritzlar, 2018, for constructs specific to mathematics, or Sternberg and O'Hara (1999), for general constructs). A positive relationship was shown, for example, in the studies by Leikin and Lev (2007) for students in grade 10 and 11 . For primary school age, relationships between mathematical creativity and mathematical achievement (Kattou et al., 2013; Schoevers et al., 2018) were predominantly studied and demonstrated, partly considering high-performers as mathematically gifted students (Kroesbergen et al., 2017), thereby suggesting conclusions regarding the relationship between giftedness and creativity.

Torsten Fritzlar

torsten.fritzlar@paedagogik.uni-halle.de

1 Martin Luther University Halle Wittenberg: Martin-LutherUniversitat Halle-Wittenberg, Halle, Germany
When students are considered to be mathematically gifted if they are able to meet strong mathematical challenges (Nolte \& Pamperien, 2017), then conventional achievement tests based on regular classroom content are not suitable for identifying mathematically gifted students. With such a specific view of mathematical giftedness, to our knowledge there are no studies of possible relationships between mathematical giftedness and mathematical creativity in the primary school age range.

A specific part of this desideratum is addressed in the study presented in this paper: we examined differences between mathematically gifted third graders and peers in a mathematically high-achieving comparison group regarding creativity in inventing figural patterns. Focussing on patterns, we included a particularly important area of mathematical activity, which at the same time, due to its mathematical richness, offer manifold potentials for creativity. 


\section{Mathematical creativity in primary grades}

"Creativity is critical to mathematics." (Shen \& Edwards, 2017, p. 326) Also for this reason, there has been growing research interest in mathematical creativity in the field of mathematics didactics in recent times. Furthermore, an increasing focus of research efforts towards creativity of schoolchildren can be observed (Singer et al., 2011).

For a characterization of mathematical creativity, common indicators from general creativity research are often used, namely fluency, flexibility, originality, and much more rarely, elaboration. Another important indicator of general creativity is meaningfulness (for example in the case of artistic products) or usefulness (Gajda et al., 2017).

A specification for mathematical creativity is often made in referring of problem solving and problem posing (e.g., Silver, 1997). For example, Sriraman (2005) defines creativity as "(a) the process that results in unusual (novel) and/or insightful solution(s) to a given problem or analogous problems, and/or (b) the formulation of new questions and/or possibilities that allow an old problem to be regarded from a new angle requiring imagination" (p. 24). Thereby, the novelty or the special quality of this construct must be seen in relation to the mathematics the students have already learned and to the problems they have solved. For problem solving situations, for instance, fluency refers to solving a problem in several ways or finding several solutions for an open problem within a short time. In mathematics, however, we argue that fluency, solely quantified by the number of responses that an individual is able to construct, has only limited significance for creativity, since it is often possible to generate a large number of similar solutions through a systematic approach which requires the use of structural rather than creative mathematical thinking. Accordingly, in their study of the development of a mathematical creativity scale for middle school students, Akgul and Kahveci (2016) found that the correlation between fluency and the total score of creativity was comparatively low. Flexibility describes the diversity of solutions and approaches used, based on different thinking directions or different perspectives in approaching the problem. Originality means to produce new, uncommon, or unique ideas and solution approaches. This aspect is usually assessed in comparison with a reference group, based on which a differentiation is made between absolute and relative creativity. Proceeding from an idea to a definite plan and, thus enriching and developing the idea, is understood as elaboration (Assmus \& Fritzlar, 2018; Leikin, 2009). Related to mathematics or problem solving, usefulness means meeting the constraints of the mathematical problem or the mathematical aspects of the situation. Consequently, an original response to a problem which does not meet the given constraints could not be called creative (Gajda et al., 2017).

In the perspective of problem solving and problem posing it becomes particularly clear that creative mathematical activity combines divergent and convergent thinking, since it is about producing a diverse range of responses and subsequently evaluating, selecting, and elaborating ideas based on problem constraints and given criteria (Lubart, 2016).

Accordingly, in studies on mathematical creativity, especially open ended problems, multiple solution tasks (Leikin, 2009), or problem posing tasks (Joklitschke et al., 2019; Yuan \& Sriraman, 2011) are used. However, results are partly dependent on the tasks that are used, and not all possible problem-solving or problem-posing situations are equally suitable for enabling mathematical creativity and making it accessible for research (Leikin, 2009). On the one hand, especially for primary school students, the mathematical richness of the applicable problems is still narrowly limited. On the other hand, the low level of experience in problem solving makes different approaches and multiple solutions difficult. Therefore, open mathematical invention problems (as a special form of open-ended problems) could be particularly suitable, where subjectively new mathematical objects (numbers, patterns, geometrical figures ...) are to be created as solutions. This is in line with a modelling perspective by Assmus and Fritzlar (2018) according to which mathematical creativity in the primary school age range can emerge not only in working on problems that require only a little mathematical knowledge and varying given problems, but also in a purposeful or free creation of mathematical objects. Moreover, this might also be close to a general cross-domain understanding of creativity as a "process of bringing into being something novel and useful" (Sternberg \& O'Hara, 1999, p. 251).

\section{Mathematical giftedness and mathematical creativity in the primary grades}

Like creativity, mathematical giftedness is a partially fuzzy construct for which, among other things, it is controversial to what extent it is a domain-specific construct, how giftedness and performance relate to each other, and to what extent the construct itself and its assignment to individuals is or should be stable over time.

In numerous current studies in mathematics didactics, mathematical giftedness is seen as domain-specific and described by mathematics-specific abilities or abilities that become increasingly specific through utilization in mathematics (cf. Krutetskii 1976) as well as a certain directionality of the whole mind. Under favorable conditions, this can lead to special performances also in mathematically rich and 
demanding situations compared to peers. (The fact that special achievements are merely possible, but not guaranteed, points to the problem of identification of mathematically gifted students).

In the literature, the catalogs of abilities characterizing giftedness change, depending on the age of children and adolescents (indicating the dynamic of the construct giftedness). For middle and high school age, the characteristics developed by Krutetskii (1976) provide an empirically validated basis to describe mathematical giftedness, as follows: ability for formalized perception of mathematical material; ability for domain related logical thought; ability to think in mathematical symbols; ability for rapid and broad generalization of mathematical material; ability to curtail the process of mathematical reasoning and to think in curtailed structures; ability for switching from a direct to a reverse train of thought; flexibility of mental processes in mathematical activity; striving for clarity, simplicity, economy, and rationality of solutions; mathematical memory; mathematical cast of mind expressed in striving to interpret the environment mathematically (Krutetskii 1976, pp. 350 f.). Building on these results, researchers such as Käpnick developed and empirically confirmed a characterization of mathematical giftedness towards the end of the primary school years, which necessarily sets a somewhat specific accent adapted to age (Käpnick, 1998). Based on this result, Assmus succeeded in elaborating in particular the cognitive characteristics of mathematical giftedness in the early primary school age range (Assmus, 2018). Considering the age group we are interested in, both studies and subsequent research can provide valuable clues for describing mathematical giftedness. In summary, this can be characterized in the primary school age range in particular by the following cognitive features:

- Ability to recognize and use mathematical structures;

- Ability to memorize mathematical issues by drawing on identified structures;

- Ability to switch between modes of representation;

- Ability to reverse lines of thought;

- Ability to cope with complex mathematical situations;

- Understanding of relational concepts and ability to use relational concepts and connections;

- Ability to construct and use mathematical analogies;

- Mathematical creativity.

Results on spatial ability were ambiguous in both the study by Käpnick (1998) and the study by Assmus (2018); in a different study, well-developed spatial ability proved to be a characteristic of mathematical giftedness (Berlinger, 2015).

However, the empirical evidence for the described characteristics varies. While Assmus (2018) was able to demonstrate statistically significant differences in controlled group comparison studies regarding the first five characteristics, the traits listed in italics are based on investigations with small numbers of students and therefore can be generalized only to a limited extent. These studies thus provide only first indications that mathematically gifted primary school children also excel in mathematical creativity. In addition, the above-mentioned characteristics were generally found to be expressed to varying degrees in gifted students. Thus, mathematical giftedness does not seem to be a uniform construct even at primary school age. Indeed, mathematically gifted primary school students can differ strongly with respect to the expression of giftedness characteristics; this could also apply to mathematical creativity.

Other studies provide indications of links between (mathematical) giftedness and creativity, but they often refer to other age groups. For example, Lev \& Leikin, (2017) examined the mathematical creativity of students in grades 10-12 with multiple solution tasks and compared four groups of students who differed in terms of IQ (gifted vs. non-gifted) and mathematical achievement (with vs. without mathematical expertise). Gifted students with mathematical expertise consistently had the highest creativity scores, while nongifted students without mathematical expertise had the lowest. In addition, mathematical expertise was identified as a prerequisite for high fluency and flexibility, and giftedness as a prerequisite for originality and creativity in general. Pitta-Pantazi et al. (2011) also investigated relationships between mathematical creativity and mathematical giftedness by having students in grades $4-6$ complete multiple solution tasks as well as a test of mathematical abilities. A theoretical model that considers both mathematical abilities and creativity as components of mathematical giftedness was statistically tested. The confirmatory factor analysis supported this model, with mathematical abilities contributing more to explaining the construct of mathematical giftedness than mathematical creativity. However, this study did not compare student groups (gifted vs. non-gifted); rather, mathematical giftedness was conceptualized as a potential that was more or less pronounced across the entire achievement spectrum. Moreover, with such a study design it remains unclear how many mathematically gifted students in the narrow sense described above were involved.

Correlations between mathematical abilities and (mathematical) creativity at primary school age have been demonstrated in various studies (e.g., Bahar \& Maker, 2011; Kattou et al., 2013; Kroesbergen \& Schoevers, 2017; Schoevers et al., 2018). Such correlations seem obvious in samples of the entire achievement spectrum on the one hand due to the threshold hypothesis (Jauk et al., 2013), but on the other hand, due to possible ceiling effects, it cannot be readily concluded that there are also strong correlations in the top group. Haylock (1997), for example, pointed to large 
differences in mathematical creativity among mathematically high-achieving students.

Based on this, it seems worthwhile to investigate possible relationships between mathematical giftedness and mathematical creativity in more detail in further studies, especially in the primary school age range. Thereby, particularly meaningful results could be obtained by comparative studies of mathematically gifted and high-achieving students.

\section{Abilities in dealing with mathematical patterns und structures as a characteristic of mathematical giftedness}

Since mathematics is considered the science of patterns (Devlin, 1994), dealing with patterns and structures plays an essential role from the very beginning. In primary school, this includes activities such as (a) creating, (b) reproducing, (c) varying, (d) continuing and completing patterns, describing and justifying patterns and structures, and structuring or ordering mathematical objects or situations according to self-chosen criteria (Assmus, 2017; Frobisher \& Threlfall, 1999). A prerequisite for most of these activities is the recognizing of underlying relational structures or regularities. In addition, a use of mathematical structures may be necessary, which often includes a generalization of these (Stacey, 1989). It is also possible to transfer structures to other representations or mathematical domains, which would be related to other abilities such as dealing with representations or analogies (Assmus, 2017).

For successful mathematical learning, a continuous development of competencies in dealing with mathematical patterns and structures is necessary for all children. These become a characteristic of giftedness when corresponding abilities are also shown by children solving challenging mathematical problems (Nolte \& Pamperien, 2017). Indeed, the ability to recognize and use mathematical structures in mathematically challenging situations is considered a particularly important characteristic also in other modellings of mathematical giftedness (e.g., Sheffield, 2003; Sriraman, 2005; Wieczerkowski et al., 2000) and a prerequisite for other traits in the descriptions above. In the studies by Käpnick (1998) and Assmus (2018), mathematical giftedness could be demonstrated for activities (a)-(d).

For the initiation and investigation of pattern activities, tasks of type (d) play a special role - both for mathematically gifted students and for the entire achievement spectrum. In this context, figural patterns are used in particular. We understand figural patterns as patterns formed by a sequence of figures consisting of single elements which is based on a regular relationship (Rivera, 2010a). A distinction is usually made between 'repeating patterns' and 'growing patterns'. Repeating patterns are characterized by a periodic structure in which a basic unit of objects recurs regularly (Zazkis \& Liljedahl, 2002). Growing patterns are understood as those in which figures are systematically enlarged or reduced in size (Lüken et al., 2014).

Dealing with growing figural patterns is particularly important for the initiation and development of algebraic thinking (Rivera, 2010a; Warren \& Cooper, 2008). Here the focus is on the generalization of mathematical relationships describing the pattern's structure (Carraher et al., 2008; Rivera, 2013) which, for example, can be used to continue the pattern figure by figure, to determine more distant figures directly (far generalization; Stacey, 1989), or to formulate algebraic generalizations (Radford, 2006). Generalizing is considered very challenging, especially for younger students (Rivera, 2010b; Stacey, 1989). However, studies with mathematically gifted or high-achieving students have shown that they are more successful than their peers in these activities. (Assmus, 2018; Fritzlar \& Karpinski-Siebold, 2012; Käpnick, 1998). Connections between mathematical ability or giftedness and success in pattern generalization tasks are obvious because pattern generalization requires a variety of competencies in dealing with numbers and number relationships, with shapes and similarity, and with figural properties (Rivera, 2013, 2018).

An analysis of the test items in studies on mathematical giftedness and abilities in dealing with mathematical patterns makes clear that tasks on figural patterns and the recognition and use of mathematical structures that mainly address convergent thinking were predominantly used. Divergent thinking, on the other hand, was hardly involved.

Other literature on creativity and mathematical giftedness also gives no indication that the creative work with patterns and structures was explicitly considered.

\section{Creating figural patterns}

Especially, growing figural patterns offer manifold potential for creative activities, since they represent geometric-figural as well as arithmetic structures, which can be described very differently depending on the particular focus. The resulting different structurings and perspectives of the same pattern offer numerous possibilities for variation. Thus, a sequence of numbers can be represented by different figural shapes, and even visually very similar figures can be based on different sequences of numbers. Especially for the creation of children's own figural patterns there is a large range of possibilities in contrast to many multiple solution tasks.

The creation of figural patterns is mentioned in literature on the didactics of mathematics as a possible classroom activity, but we are not aware of systematic research concerning primary school children. For older pupils and students, this topic has been examined from different 
perspectives. For example, Rivera and Becker (2016) investigated pattern generalization of seventh- and eighth-grade students in so called semi-free tasks. Here, students were asked to find two different continuations of figural patterns, given the first figure or the first two figures. Starting with equations of linear or quadratic functions, Wilkie (2019) had secondary students (year 7-year 12) invent figural patterns and, in another study, Wilkie (2021) investigated how prospective teachers invent figural patterns based on quadratic functions. Here, the creation served to stimulate conceptual meanings for linear or quadratic functions. Under the focus of creativity, Vale et al. (2012) used a task in a study with student teachers in which figural patterns were to be created with a given figure in the first or second position. However, due to time constraints, this task was completed by only a few students, and an intraindividual variety of solutions did not emerge.

\section{Research interest}

We are interested in which figural patterns third graders create in a given period of time using materials and how they do this. Because we focus on mathematical creativity, it seems important to us to ensure a mathematical substance of the task by defining mathematical constraints. Therefore, the invention should not take place completely freely, but on the condition that the first two figures should consist of one and five elements, respectively. The tasks can thus be understood as semi-free task (Rivera \& Becker, 2016) or open-ended problem. The focus is on comparing mathematically gifted children with peers.

Therefore, the study was based on the following research question: How does mathematical creativity in creating figural patterns differ among mathematically gifted and nongifted third graders?

We have argued that fluency often has little informative value regarding mathematical creativity. This is also true for the creation of figural patterns for the same reasons. The originality of results and approaches can be examined easily by comparing them in the study group. Determining flexibility in creating figural patterns, on the other hand, seems to be a challenge; criteria are needed that can be used to evaluate the variety of the figural patterns. If it is possible to work out such criteria, it could also be helpful to identify "flexibility types' for group comparisons. This gives rise to two further subordinate research questions:

a. How can the processes and products of creating figural patterns be described in a differentiated way regarding (the construct of) mathematical creativity?

b. Which types of mathematical flexibility can be constructed?

\section{The realization of an interview study on creating figural patterns}

\subsection{Data collection}

For data collection, semi-standardized individual interviews were conducted, in which the participating primary school students were asked to create as many different figural patterns as possible using wooden cubes of the same size and with the numbers 1 and 5 given for the first two figures.

The interview consisted of three phases: in an introduction phase, special features of figural patterns were explained by video using two examples (sequence 1 - the first three figures of the square numbers realized with counters; sequence 2-figures with one and three counters placed at right angles) by continuing them (differently) and explaining various rules (referring to the shape of figures, their growth, arithmetic relations ...). The video was interrupted by two short activity phases, in which the students were asked to place a possible next figure, using counters, to continue the given beginning of a figural pattern and to state a rule.

In the 30-min working phase, the students could take cubes from a bag and create figural patterns using them. The first four figures were to be represented in each case. For every invented pattern, students were asked to orally state an underlying rule, to show 'where you can see the rule in the pattern' and to record it in writing on a notepad. Pattern and notepad were finally photographed by the interviewer using a tablet.

In the subsequent reflection phase, the students were shown the photos of the patterns and they were asked to select the most interesting figural pattern and to justify the selection. In addition, they should report their approaches for creating patterns.

The interviews were videotaped and transcribed in essential parts. Based on this, a very detailed protocol (including text and images) of working processes and products as well as verbal expressions and gestures of all persons involved was produced for each interview.

\subsection{Selection of participants}

We selected the study participants from a group of 75 third graders $(61 \mathrm{~m}, 14 \mathrm{f})$ who had registered for a gifted education project at the Martin Luther University HalleWittenberg in Germany at the beginning of the school year in 2020 and who had taken an entrance test. The students were nominated by their teachers whom we had asked to suggest mathematically gifted children for the project from 
their point of view. Since we also collected their school grades in mathematics, we could be sure that all participating students were at least mathematically high achievers.

The entrance test comprised five tasks with several subtasks each. In the selection and construction of the test items, we aimed to address a wide range of essential characteristics of mathematical giftedness (cf. Sect. 3) without explicitly eliciting creativity. These characteristics are substantially based on Krutetskii's investigations of older students, which had been confirmed and specified in later studies for the primary school age range (e.g., Assmus, 2018; Käpnick, 1998). Thus, the test included at least one item each for the following characteristics of mathematical giftedness:

- Ability to memorize mathematical issues by drawing on identified structures Task 1a, 1b: memorizing structured number arrangements (Assmus, 2018; Käpnick, 1998)

- Ability to recognize and use mathematical structures Task 2a, 2b, 2d: determining numbers of elements in figural patterns using near and far generalization (Assmus, 2018); Task 4a: Recognizing and describing rules in structured number arrangements (Käpnick, 1998)

- Ability to transfer mathematical structures Task $4 \mathrm{~b}$ : constructing an analogous number arrangement (Käpnick, 1998)

- Ability to reverse lines of thought Task 2c, 3b: working on a reverse question (Fuchs \& Käpnick, 2004)

- Ability to switch between modes of representation Task 2: working on tasks in which a change from pictorial to symbolic representations becomes necessary (Assmus, 2018)

- Ability to use relational concepts and connections Task 3a: working on a mathematical problem in which relationships between data must first be discovered and used for the solution (Fuchs \& Käpnick, 2004)

- Spatial reasoning Task 5a: spatial relations, Task 5b: visualization, Task 5c: spatial orientation (Berlinger, 2015; Thurstone, 1950).

Based on the test results, we identified two groups of students with the highest and lowest test results, each comprising 20 students. From these groups, those children were selected who were willing to participate in the interview. Finally, we found 14 students $(13 \mathrm{~m}, 1 \mathrm{f})$ in the group of children with the highest results (gifted group $\mathrm{G}$ ) and 10 students $(8 \mathrm{~m}, 2 \mathrm{f})$ in the comparison group of lowest results (comparison group C). The low proportion of girls in both groups is consistent with the widespread underrepresentation in extracurricular math-related activities (math clubs, math competitions ...).

As various studies have shown, tasks used in the entrance test are suitable for assessing the characteristics of mathematical giftedness at primary school age (Assmus, 2018;
Berlinger, 2015; Käpnick, 1998). We therefore designate the students in group $\mathrm{G}$ as mathematically gifted. However, we are aware of the fact that this designation has yet to be confirmed in a longer diagnostic process during the university project.

All students from group $\mathrm{G}$ were selected to participate in the university course, which started directly after the interviews were completed. At the time of the interview, the students and the interviewer did not know the outcome of the selection process.

\subsection{Data analysis}

Our data analysis consisted of the following analysis steps:

a. Identification of valid figural patterns created by the participating students.

b. Determination of characteristics for the differentiated description of valid figural patterns.

c. Elaboration of specific flexibility profiles of students' creations based on several dimensions of variety.

d. Type formation concerning flexibility.

e. Identification of figural patterns with originality.

f. Comparison of groups $\mathrm{G}$ and $\mathrm{C}$.

The procedures for the analysis were based on the steps of qualitative content analysis using deductively-inductively gained categories (step b; e.g., Mayring, 2014) and inductive type formation (step c, d; Kuckartz, 2014). In each case, the analysis was based on the interview transcript and the photos of the figural patterns. All analysis steps were first completed individually by both authors, checked for agreement, discussed in case of discrepancies, and brought to agreement. Up to step f, we had no information on the students' membership of the group $\mathrm{G}$ or $\mathrm{C}$.

\subsubsection{Step a: identification of valid figural pattern}

A figural pattern was classified as valid if it had mathematical regularities with consideration of the given numbers 1 and 5. The regularities could refer either exclusively to the numbers of used cubes or to both numbers and geometric shapes. However, we did not consider vague form resemblances as in Fig. 1a, since an exact regularity within the four figures is not given in this case.

The specification of number 1 for the first figure opens up many different possibilities in the continuation, but the shape of the figure itself is not variable. Since it may not be obvious for children to pay attention to form aspects beginning already from, figure 1 figural patterns are also considered as valid if they show number and form regularities beginning from figure 2 (see Fig. 1b). 

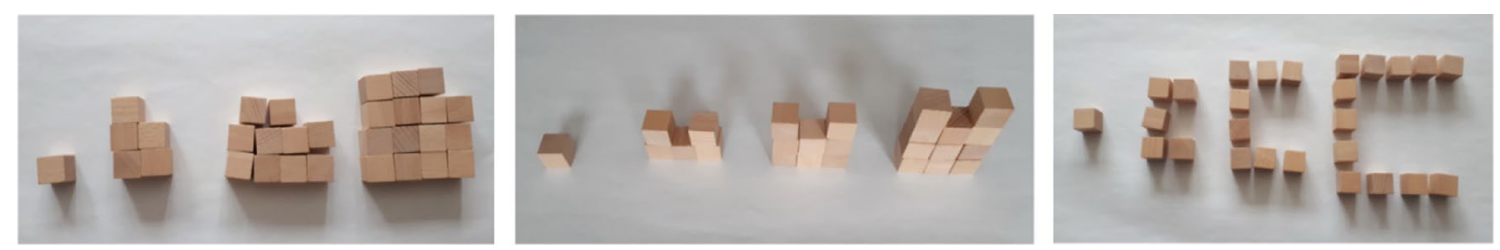

Fig. 1 a-c Patterns with vague form resemblances; regularities beginning from figure 2; minor errors

The decisive factors for the evaluation of figural patterns were the numbers and the arrangement of the cubes in the individual figures, the process of constructing the figures, and the regularities mentioned by the students. If this information showed that the children were aiming for mathematical regularity but did not implement it completely correctly due to minor errors in the counting or building processes, we ignored these errors and recognized the pattern as valid (see Fig. 1c).

\subsubsection{Step b: determination of characteristics for the differentiated description of valid figural patterns}

The goal of the second analysis step was to identify as many characteristics and related states as possible for a differentiated description of the valid figural patterns. On this basis, we could identify those characteristics that could be useful for describing the variety in the sense of flexibility in the invention process in the next step c. Step b required a view on the results and processes to be as open as possible. Therefore-partly deductively, partly inductively—characteristics to describe differences between the patterns as well as possible states were worked out and underpinned with examples. These features included, for example, the modality of the underlying regularity (number, shape, number and shape), the continuability of the figural patterns (yes, no), the focus of the oral/written descriptions (e.g., number, shape, construction, building process), and the orientation of the building process (e.g., on numbers, rules, shapes).

\subsubsection{Step c: evaluation of the flexibility of students' creation of figural patterns}

How can we assess the flexibility of a student's creation of figural patterns? A measure of this flexibility can be the variety of the generated patterns and, to a lesser extent, their descriptions. It was therefore necessary to identify those characteristics from step $b$ which describe this variety in a differentiated and at the same time practicable way, taking into account the mathematically essential attributes of created figural patterns. Based on this, we developed the following description system:
- Type of mathematical relations: Which mathematical relation underlies (the regularity of) the figural pattern (e.g., constant increase, uniformly changing increase, alternating arithmetic change, repetition of figures and numbers, calculation based on cube numbers of preceding figures)?

- Shape: What regularly changing shape emerges in the figural pattern (e.g., cross, bar, L, pyramid)? Shapes were considered to equal if they could be moved into each other within the same plane or if they differed only by the distances between adjacent cubes.

- Building principle: How are the figures built and aligned to the top of the table (e.g., in multiple layers, lying in one layer, standing in one layer)? At which points do adjacent cubes touch each other (e.g., noncontact, area-wise contact, edge-wise contact)? How are adjacent cubes aligned to each other (e.g., shifted cubes, rotated cubes)?

- Number of extension directions: In how many directions are the figures extended from step to step (e.g., bar: 1, L: 2, cross: 4)?

- Focus of the student's oral descriptions: To which aspects does the orally formulated rule refer (e.g., number, shape, building process)?

Thereby, the mathematical features 'type of mathematical relations' and 'shape' are rated as particularly important, and the focus of oral descriptions as least important due to their solely communicative function.

A valid figural pattern can be described in detail by these characteristics or the respective states. On that basis, the numbers of different states of a student's set of figural patterns characterize the flexibility of her/his creation. This flexibility profile can be visualized very clearly in a radar chart (also known as, e.g., a spin web chart) in which the different importance of the characteristics justified above is implemented by a differentiated scaling of the axes in the ratio 3:2:1. The resulting graph describes the student's invention in relation to the five variety dimensions, as follows: number of types of mathematical relations, number of shapes, number of building principles, number of types of expansion characterized by the respective numbers of extension directions, number of focusses of the student's oral descriptions. 


\subsubsection{Step d: type formation concerning flexibility}

The aim of this step was to identify different types of creation of figural patterns concerning flexibility. For type formation, the person-related radar charts were analyzed regarding similarities and differences. The starting point of comparison was the approximate size, shape, and orientation of the area spanned by the graph. From this, the numerical values of the flexibility profiles were compared in detail.

The number of types was not determined in advance but resulted from the grouping of the individual cases. As is usually done in inductive approaches, the aim was not to achieve a complete match of flexibility profiles, but rather to form polythetic types consisting of particularly similar profiles (Kuckartz, 2014).

\subsubsection{Step e: identification of figural patterns with originality}

In this step, we checked the originality of the figural patterns related to the described characteristics (step c). Thereby, a state was considered original if it was unique within the study, i.e., if it occurred in only one pattern. A figural pattern can thus be original related to various characteristics (type of mathematical relation, shape, building principle, number of extension direction). However, the focus of oral descriptions cannot be original because it is not a feature of the created pattern.

For each original state, a star is added to the associated scale in the radar chart.

\subsubsection{Step f: comparing the groups $G$ und $C$}

For all students involved in the study, we determined their membership in groups $\mathrm{G}$ and $\mathrm{C}$. On this basis, we were able to compare both groups concerning the average numbers of valid figural patterns, their distribution among the formed flexibility types and the originality of created patterns.

\section{Findings}

\subsection{Flexibility of creating figural patterns}

In step d, all radar charts and underlying flexibility profiles were compared in detail. Based on this, we worked out-each author separately with subsequent consensual validation-the following five types describing flexibility in creating figural patterns:

- Type 1a: diversely varying.

- Type $1 \mathrm{~b}$ : diversely varying with geometric focus.
- Type 2: geometrically varying based on constant growth.

- Type 3: arithmetically varying.

- Type 4: sparsely varying based on constant growth.

- Type 5: not or hardly varying.

In the following, we present essential characteristics of the types and the corresponding radar charts. For types with particularly conspicuous profiles (type $1 \mathrm{~b}$ and type 5), cases will be presented in more detail.

\subsubsection{Type 1a (diversely varying; two students)}

Distinctions of the flexibility profile: All components higher than one, at least three types of mathematical relations and three different shapes.

General description: In this type, the students created five or eight figural patterns. For the most part, they consciously generated different arithmetic rules that were then realized with the cubes. For a large part, but not always, students also considered shape regularities; linear shapes (bars) were sometimes used several times. Almost all invented patterns were valid with regularities beginning from the first figure. In the realization of the shape regularities, students used different building principles and different types of expansion. The focus of the oral descriptions varied as well (Fig. 2).

\subsubsection{Type $1 \mathrm{~b}$ (diversely varying with geometric focus; four students)}

Distinctions of the flexibility profile: All components higher than one, two types of mathematical relations, at least four different shapes.

General description: In this type, students created between six and eight figural patterns. Almost all patterns were valid and, with a few exceptions, showed both numerical and shape-related regularities. In addition to constant growth, another mathematical relation was used, mostly change with uniformly changing increase. All other characteristics varied as well (Fig. 3).

Adam created eight different figural patterns (Fig. 4). Except for pattern 8, all of them were valid and showed regularities concerning number and shape. In the patterns 1, 3, 4 and 5, a constant growth beginning from the second figure was realized in each case (plus 2, plus 5); in pattern 2 , there was constant growth beginning from the first figure (plus 4). Figural patterns 6 and 7 were based on a uniformly changing increase (difference increasing by 4 , difference increasing by 3 ). Adam had thus created both linear and non-linear growing figural patterns.

The figural patterns 1 and 2 as well as 3 and 4 had the same shapes (L, bar); all other shapes were different. Two building principles could be identified: laying in one layer 


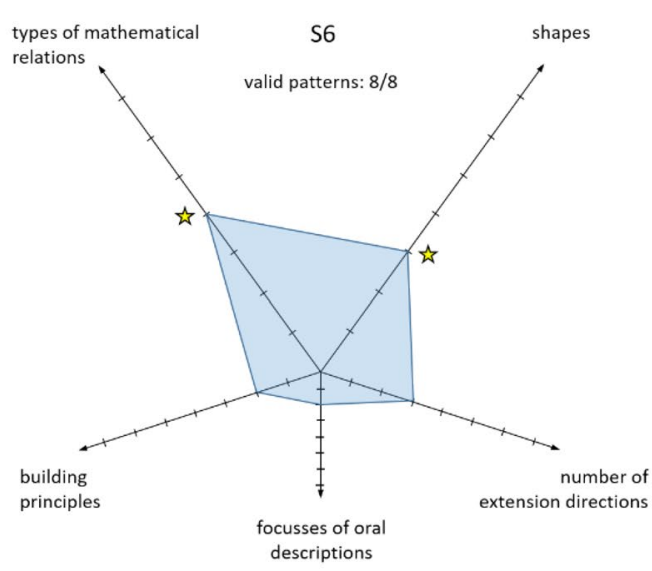

Fig. 2 Radar charts of type 1a

with area-wise contact of adjacent cubes (patterns 1 to 6 ) and building in multiple layers (pattern 7). Figures were extended in one direction (patterns 3 and 4), in two directions (patterns 1,2,5) and in four directions (patterns 6, 7). In the oral descriptions, Adam described in most cases the position and number of added cubes (pattern 2: "Now it fits

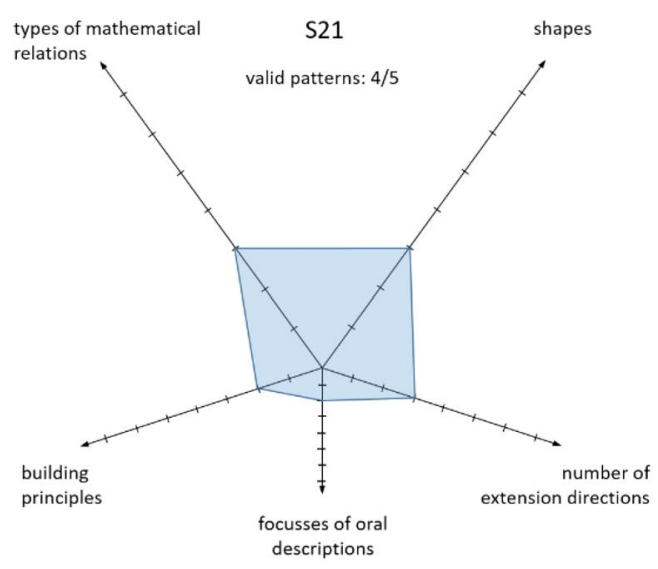

that on the right and above always two are added."). Once he mentioned arithmetic relations (pattern 6: "So, first plus four, then plus eight, and then plus twelve. Thus, always four more."; all statements translated by the authors).

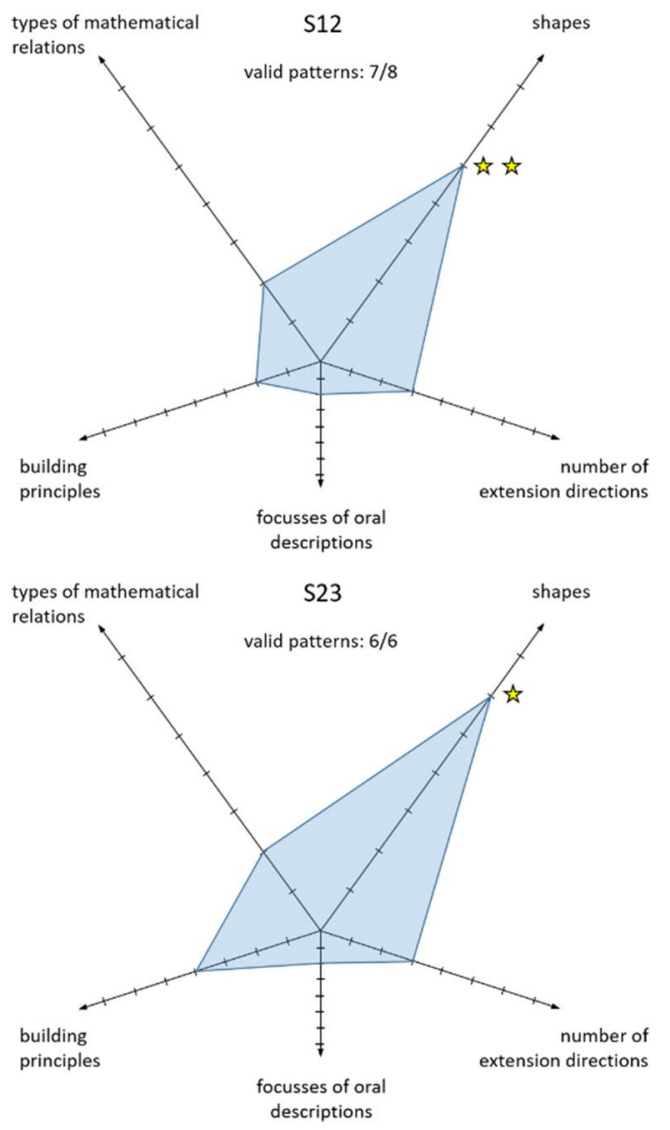

Fig. 3 Radar charts of type $1 \mathrm{~b}$ 


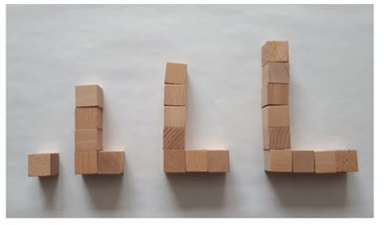

Figural pattern 1

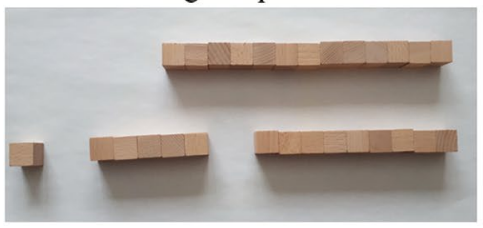

Figural pattern 4

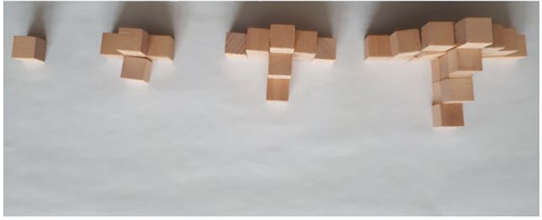

Figural pattern 7

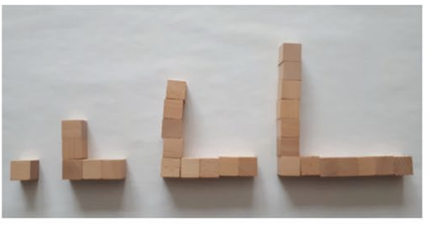

Figural pattern 2

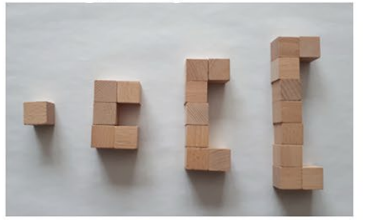

Figural pattern 5

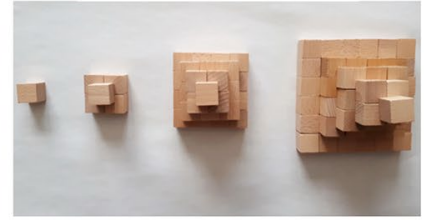

Figural pattern 8

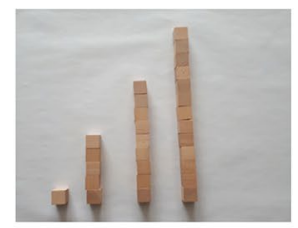

Figural pattern 3

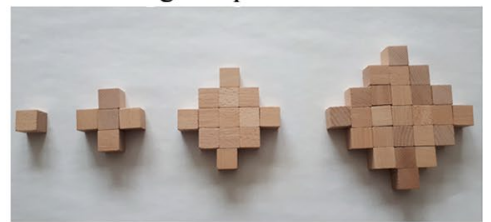

Figural pattern 6

Fig. 4 Figural patterns invented by Adam

\subsubsection{Type 2 (geometrically varying based on constant growth; four students)}

Distinctions of the flexibility profile: one mathematical relation (constant growth), at least four different shapes, at least one further component higher than one.

General description: In this type, students created between five and nine figural patterns. For all students, the rule "plus 4" played an essential role, but it was consistently used with different shapes, so that for almost all students, at least four different patterns with different shapes and constant growth by 4 could be identified. All other figural patterns were also based on a constant growth but starting from the second figure. For nearly all students all patterns were valid and showed regularities in shape and number. Different types of expansion were used, but variations in the building principles occurred only rarely. All students described laying processes and possibly another regularity of shapes or numbers (Fig. 5).

\subsubsection{Type 3 (arithmetically varying; two students)}

Distinctions of the flexibility profile: At least three mathematical relations, in all other components no or very few variations.

General description: In this type, students created seven or eight figural patterns. In doing so, they started from numbers and purposefully searched for different arithmetic rules. Either these rules were realized consistently in linear cube arrangements or shape regularities are not mentioned at all. The missing shape regularities or variations also influenced the variety of used building principles and types of expansion. The students' descriptions hardly differed in their type, since nearly all were formulated arithmetically (Fig. 6).

\subsubsection{Type 4 (sparsely varying based on constant growth; five students)}

Distinctions of the flexibility profile: One mathematical relation (constant growth), two or three different shapes, variation of at least one further component.

General description: In this type, students created between four and six figural patterns. The vast majority of patterns were valid, all rested on constant growth. Creating mainly started from numbers, but all students also tried to produce regularities concerning shapes. This was successful in at least half of the created figural patterns. Each student used two different building principles. For almost every student there was also a variation of a further characteristic (Fig. 7).

\subsubsection{Type 5 (not or hardly varying; six students)}

Distinctions of the flexibility profile: Variation concerning at most one component (two states).

General description: In this type, creating mainly started from numbers. Thereby, either hardly any continuous regularities were realized (two students), the regularities were exclusively related to numbers (three students), or the used shapes resembled each other and were only changed in position (one student). With one exception, students used only constant growth as mathematical relation (mostly plus 4). 

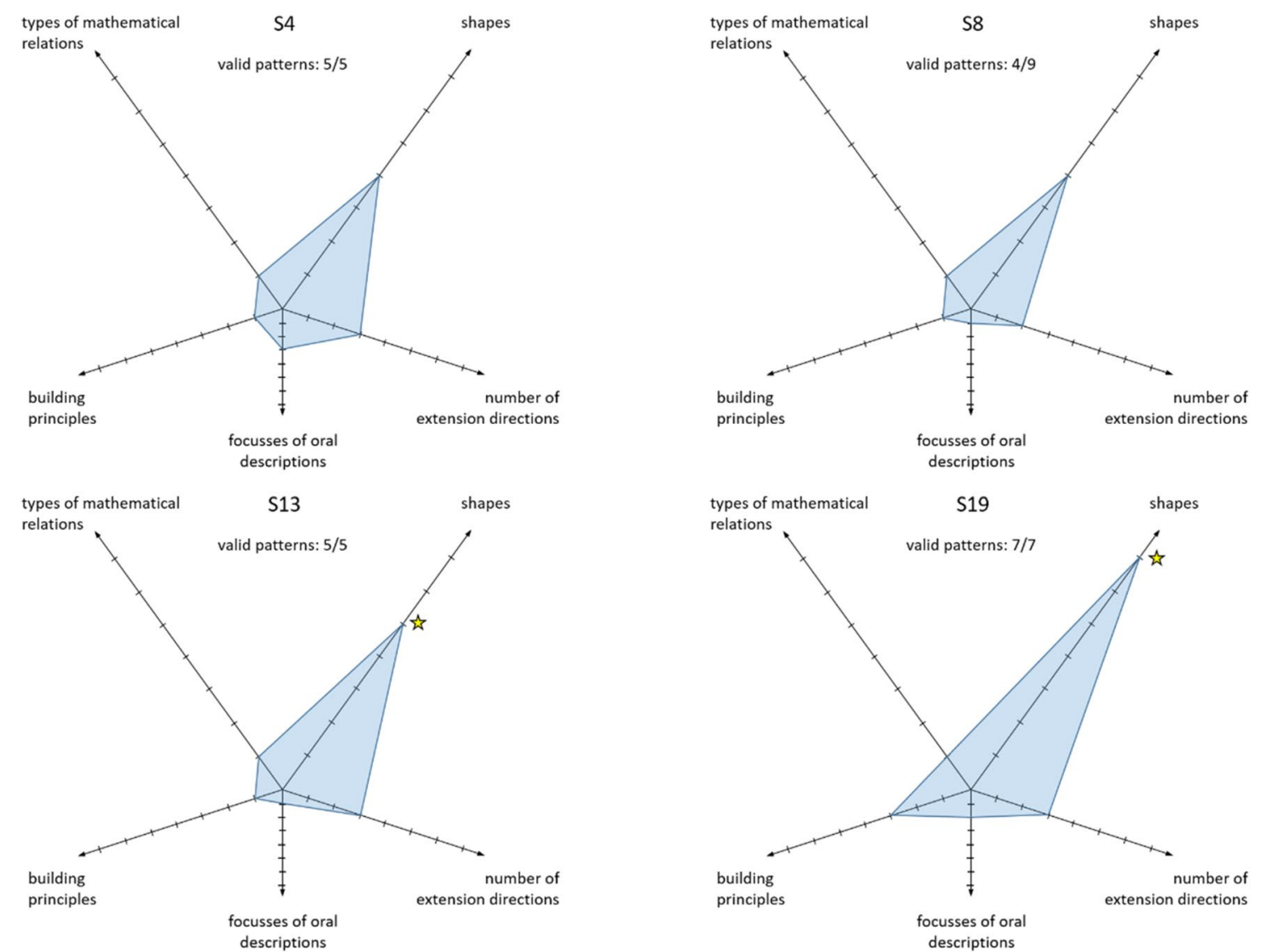

Fig. 5 Radar charts of type 2
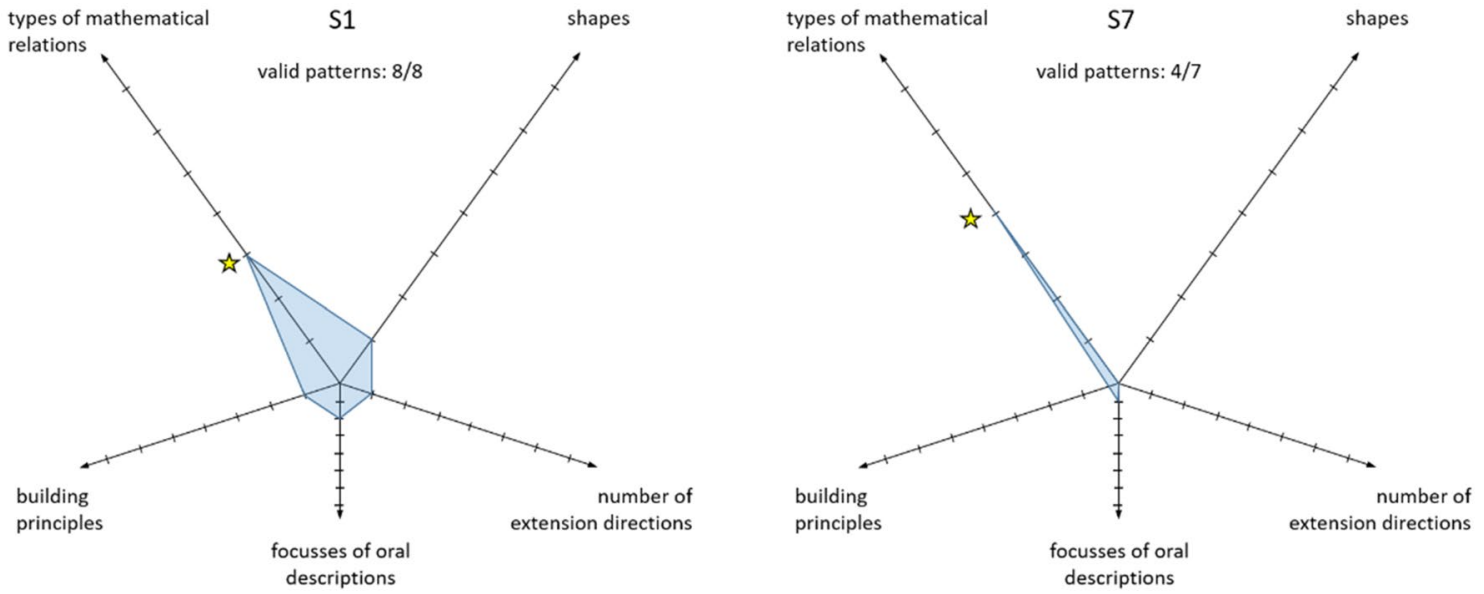

Fig. 6 Radar charts of type 3

The oral descriptions referred for the most part to arithmetic operations. The characteristics 'building principles' and 'number of extension directions' did not vary. Overall, variety was not apparent with regard to any characteristic (Fig. 8).

Chen created seven different pattern sequences (Fig. 9), but only two of them based on constant growth have been 

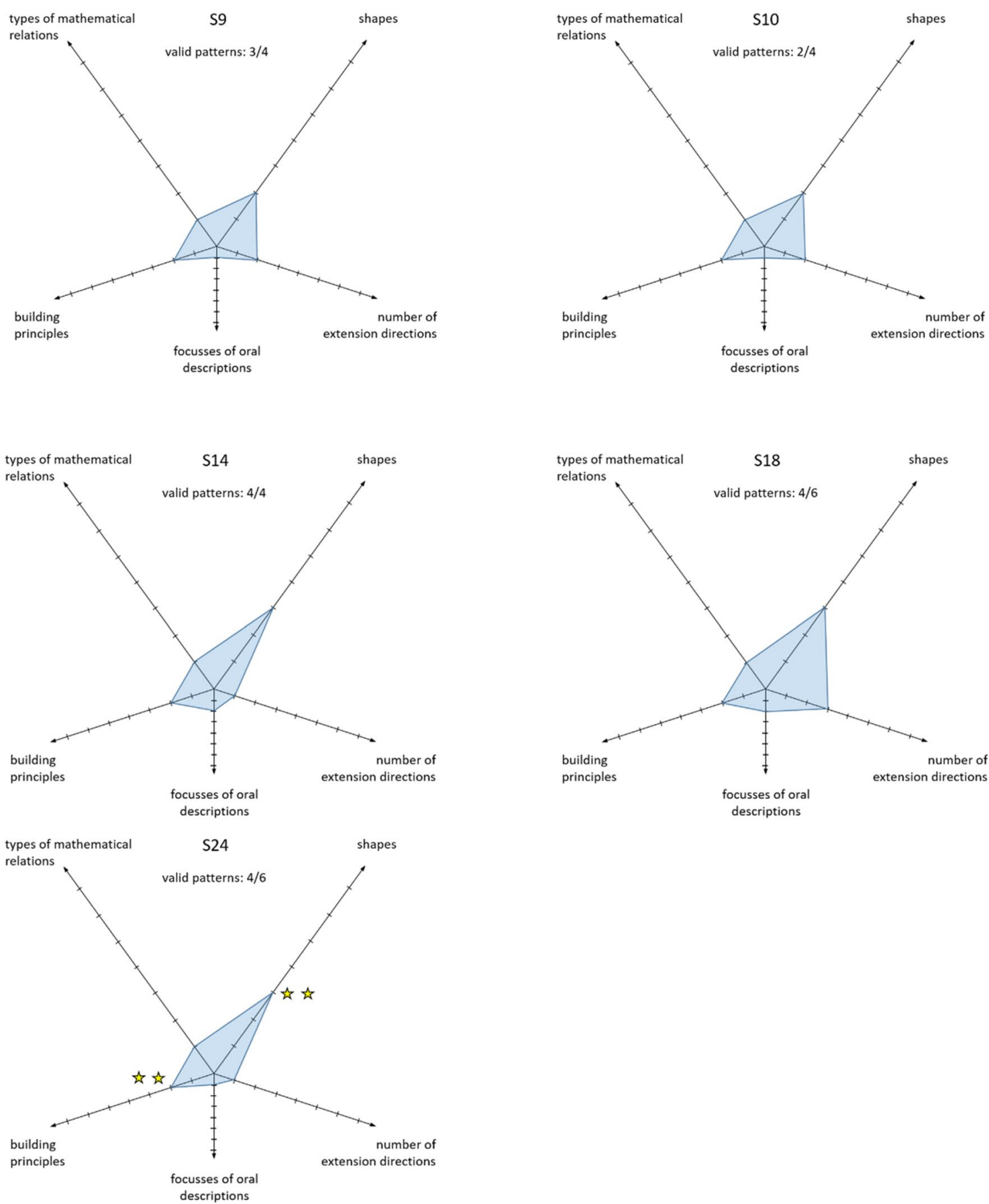

Fig. 7 Radar charts of type 4

judged valid. These were pattern 1 having a purely numerical regularity (plus 4), and pattern 5 with regularity in shape and number beginning from figure 2 (plus 2). All other sequences did not show continuous regularities.

Since there was only one pattern with regularity in number and shape, there was also only one state of the characteristics 'building principles' and 'number of extension directions'. The descriptions of the valid sequences referred to arithmetic relations (pattern 1: "I always took four in addition") or the form of the figures (pattern 5: "that then a larger $\mathrm{L}$ arises, then again a larger $\mathrm{L}$ and then again a larger $\mathrm{L}$. .").

Special characteristics of the invalid patterns stand out: the arrangement of the cubes in figural patterns 2, 3, 4, 6 is similar to pattern 1 and the types of related descriptions 

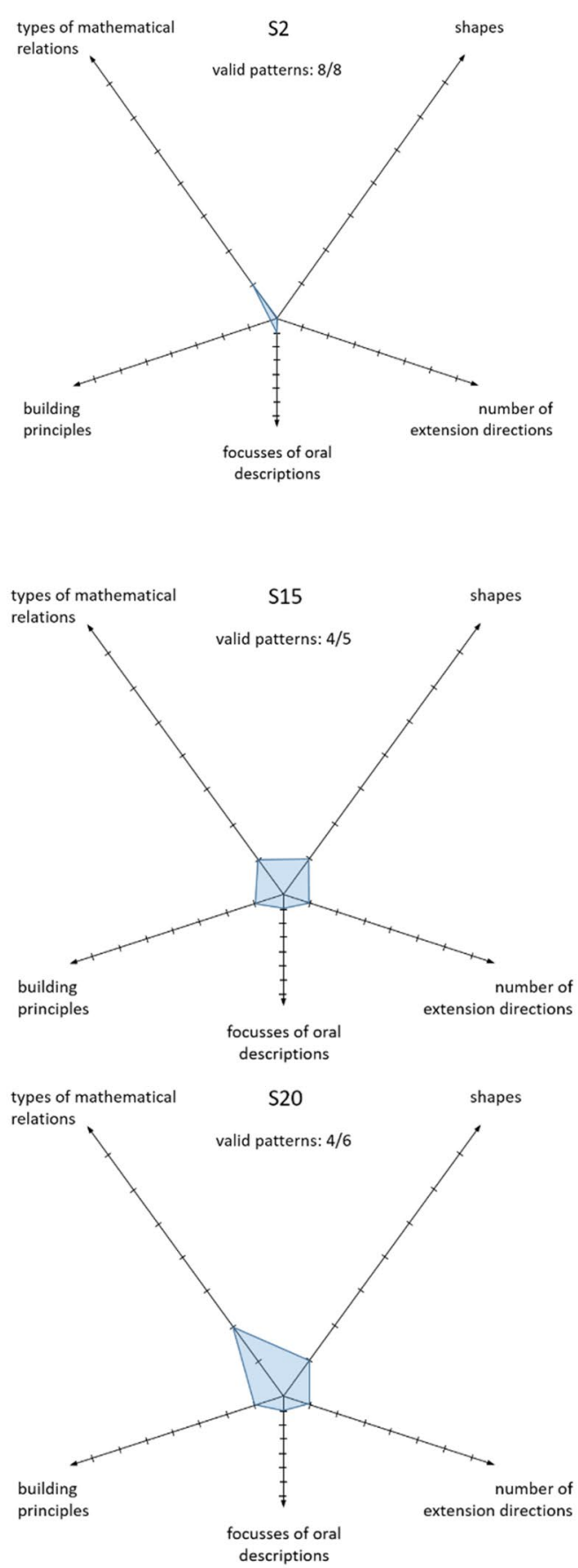

Fig. 8 Radar charts of type 5

also correspond to it. Pattern 7 in turn resembles pattern 5, which is also evident in the student's descriptions: in both, reference is made to a letter.

After a student had created a figural pattern, he or she was always asked to show where the underlying rule can be seen. For sequences 2, 3, 4, and 6, it was clear from the corresponding information that Chen did not think of the smaller figures as contained in the larger ones. Thus,
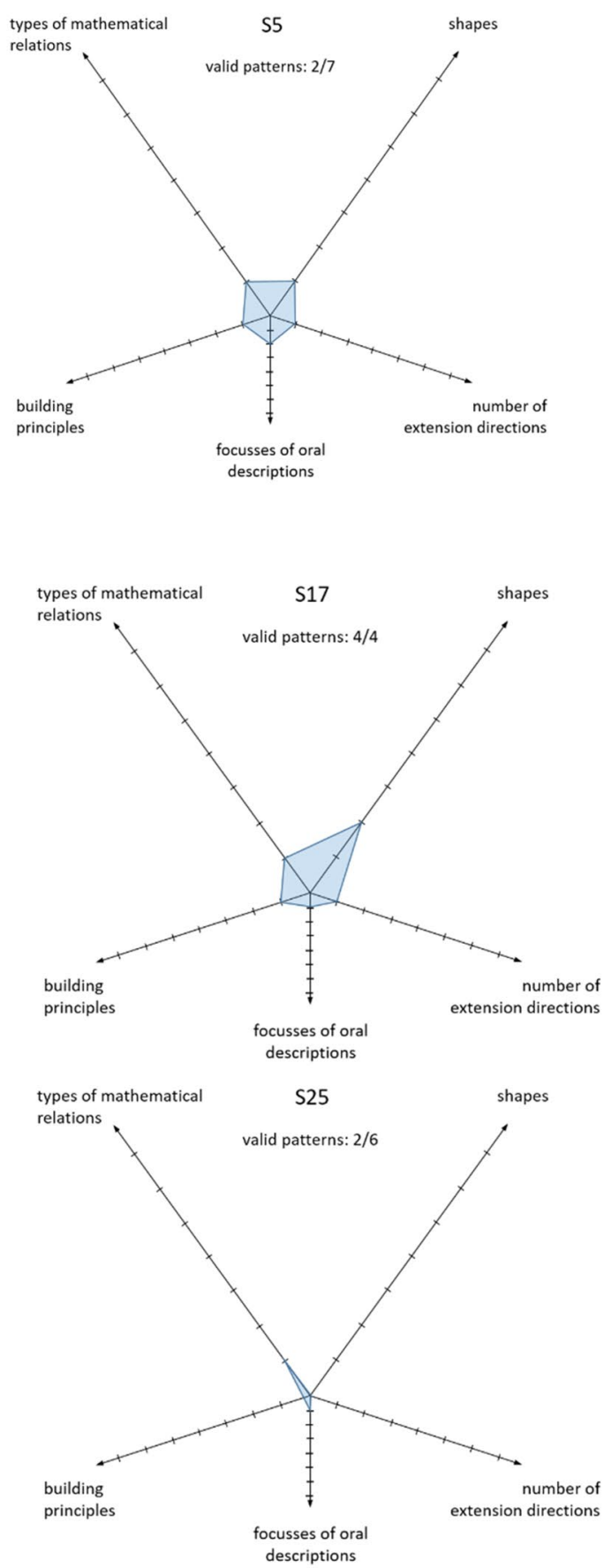

cubes in the same position were sometimes shown as added cubes. This indicates that Chen used the figures exclusively as representatives for the respective numbers and that no further connections between the figures of a sequence were established.

From this, it can be concluded that Chen paid attention either to the numbers or to shapes; there was no conjunction of these two views. Therefore, he did not meet basic 


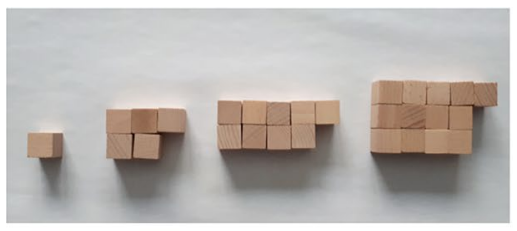

Figural pattern 1

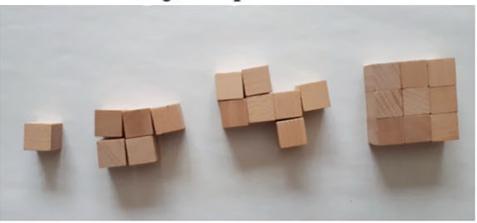

Figural pattern 4

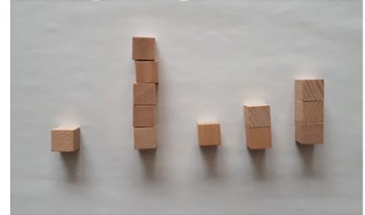

Figural pattern 7

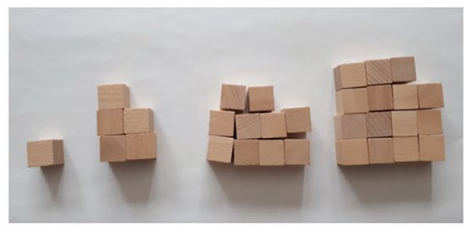

Figural pattern 2

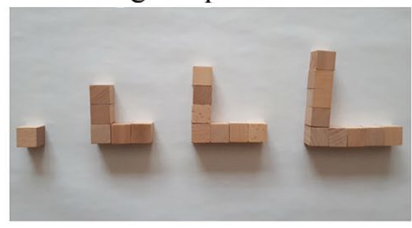

Figural pattern 5

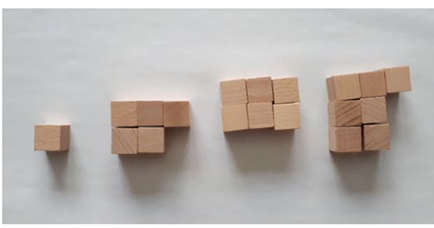

Figural pattern 3

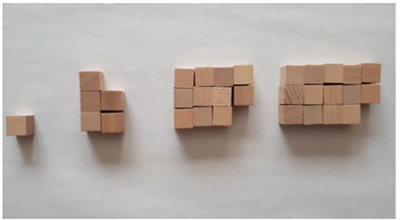

Figural pattern 6

Fig. 9 Figural patterns invented by Chen

Table 1: Comparison of groups $\mathrm{G}$ and $\mathrm{C}$ concerning the number of created figural patterns (patterns enumerated in the first three rows are valid)

\begin{tabular}{llc}
\hline Modality of mathematical relation & \multicolumn{2}{c}{$\begin{array}{l}\text { Average number of } \\
\text { patterns per student }\end{array}$} \\
\cline { 2 - 3 } & Group G & Group C \\
\hline $\begin{array}{l}\text { Number and shape beginning from the 1st } \\
\text { figure }\end{array}$ & 3.3 & 0.8 \\
$\begin{array}{l}\text { Number and shape beginning from the 2nd } \\
\text { figure }\end{array}$ & 1.1 & 1.4 \\
number & 1 & 1.8 \\
$\begin{array}{l}\text { No regularity } \\
\text { Total }\end{array}$ & 0.9 & 1.6 \\
\hline
\end{tabular}

requirements for successful mastery of the creation task, which made creative action in this context difficult.

\subsection{Originality}

We could find uniquely occurring states of the characteristics 'type of mathematical relation', 'shape' and 'building principles'.

Altogether, students created 18 different shapes including very frequently typical shapes such as bar, cross, $\mathrm{L}$ and $\mathrm{T}$. The following ten shapes were unique. The patterns created by $\mathrm{S} 13$ to $\mathrm{S} 24$ are linear growing patterns with increment 4; the patterns created by S6 and S12 are non-linear ones.

In addition to the mostly predominant constant growth, we identified six other mathematical relations. Three of them occurred uniquely: the sum of square numbers (see
S6 in Fig. 10), a pattern with alternating increasing growth $(+1,+4,+2,+5)$, and the calculation with numbers of elements of previous figures (Table 1 ).

We could find seven different building principles. Two of them were used only once. So, S24 used the cubes twisted in relation to each other or put them shifted on top of each other (see Fig. 10).

\subsection{Comparison of groups $\mathbf{G}$ and $\mathrm{C}$ regarding different aspects of creativity}

\subsubsection{Number and validity of created figural patterns as well as modality of the underlying mathematical relation}

As it can be seen in Table 1, students in group $\mathrm{G}$ created slightly more figural patterns on average (6.3) than the children in group $\mathrm{C}$ (5.6). The differences become clearer when we look at the valid patterns (G: 5.4, C: 4.0). Therefore, fluency in creating figural patterns is on average higher in the group $\mathrm{G}$ of gifted students compared to the group $\mathrm{C}$ of students who achieved only low results in the entrance test.

Further differences become apparent when we consider the modality of the mathematical relations. While almost $70 \%$ of the figural patterns created in group $\mathrm{G}$ show both, shape and number regularities, this is the case in the comparison group only for almost $40 \%$. For shape and number regularities beginning from the first figure, group $\mathrm{G}$ showed four times the number of patterns found in group $\mathrm{C}$. 


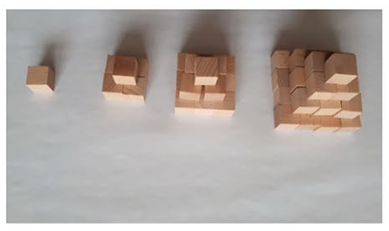

S6

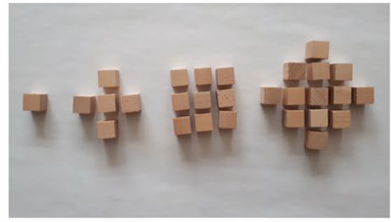

$\mathrm{S} 13$

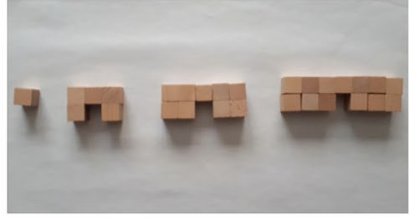

S22

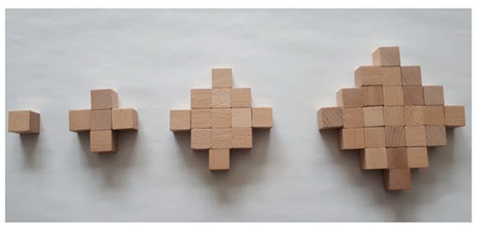

$\mathrm{S} 12$

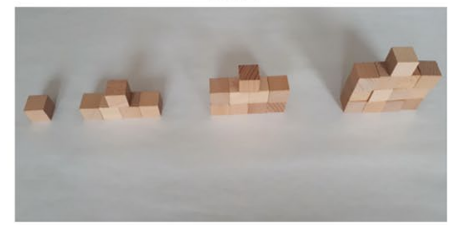

$\mathrm{S} 16$

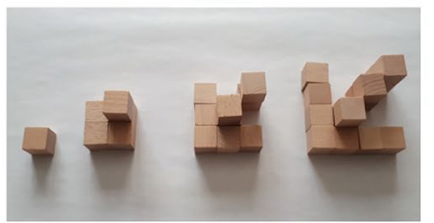

S23

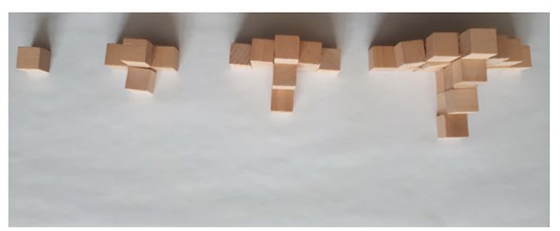

S12

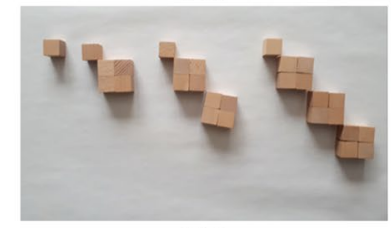

S19

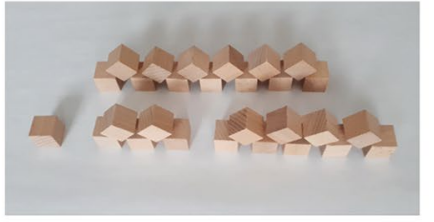

S24

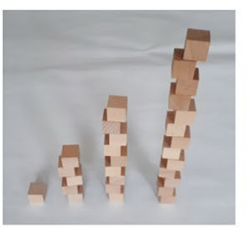

S24

Fig. 10 Unique figural patterns

\subsubsection{Flexibility}

If we look at the assignment of cases to the flexibility types and at the same time at their affiliation to groups $\mathrm{G}$ and $\mathrm{C}$, a clear result emerges. With one exception (S3), the pattern creation of all students of group $\mathrm{C}$ belongs to types 4 or 5 , i.e., they show no to little flexibility regarding the described dimensions. In contrast, the pattern creation of almost all gifted students (except for S9, S24 and S16) was assigned to types $1-3$. The pattern creation of the students with the four best results in the entrance test belongs without exception to type 1 (S6, S21, S12, S23).

Further noticeable features can be seen in the comparison regarding the characteristic 'mathematical relation': eight of the nine participating students who achieved a result in the top ten in the entrance test used at least one other type of mathematical relations in addition to constant growth. In addition, variation in the types of used mathematical relations was evident for only two other students.
Table 2 Assignment of cases to the flexibility types

\begin{tabular}{ll}
\hline Type & Cases \\
\hline Type $1 a$ : diversely varying & $\overline{\mathrm{S} 6 *}, \overline{\mathrm{S} 21}$ \\
Type $1 b$ : diversely varying with geometric focus & $\underline{\mathrm{S} 3}, \overline{\mathrm{S} 12^{*}}, \overline{\mathrm{S} 22^{*}, \overline{\mathrm{S} 23^{*}}}$ \\
Type 2: geometrically varying based on constant growth & $\overline{\mathrm{S} 4}, \overline{\mathrm{S} 8}, \overline{\mathrm{S} 13^{*}}, \overline{\mathrm{S} 19^{*}}$ \\
Type 3: arithmetically varying & $\overline{\mathrm{S} 1 *}, \overline{\mathrm{S} 7^{*}}$ \\
Type 4: sparsely varying based on constant growth & $\overline{\mathrm{S} 9}, \underline{\mathrm{S} 10}, \underline{\mathrm{S} 14}, \underline{\mathrm{S} 18}, \overline{\mathrm{S} 24^{*}}$ \\
Type 5: not or hardly varying & $\underline{\mathrm{S} 2}, \underline{\mathrm{S} 5}, \underline{\mathrm{S} 15}, \underline{\mathrm{S} 17}, \underline{\mathrm{S} 20}, \underline{\mathrm{S} 25}$ \\
Not assignable & $\overline{\mathrm{S} 16^{*}}$ \\
\hline
\end{tabular}

-: $\overline{\text { case }}$ from gifted group, : case from comparison group, *: originality assigned 


\subsubsection{Originality}

Also, from Table 2 it can be seen that exclusively gifted students invented figural patterns with original states of describing characteristics. If a gifted student had no originality, her or his pattern invention, except for S21, was assigned to types of lower or medium flexibility.

\section{Discussion}

The study presented here comprised a written entrance test for a university project fostering mathematically gifted primary students with 75 third-graders as well as 24 individual interviews of approximately $45 \mathrm{~min}$ duration. Despite the great effort involved in conducting the study, it remains a small experimental group so that only cautious conclusions can be drawn from the results. This is especially important for the assessment of originality, since the number of unique patterns may decrease with larger experimental groups.

The five variety dimensions made it possible to work out the variety of students' ideas in a differentiated way and, on this basis, to assess individual flexibility and originality concerning the creation of figural patterns. Five flexibility types emerged which differ clearly in their profiles. The profiles of types $1 \mathrm{a}$ and $1 \mathrm{~b}$ show a high degree of variation, those of types 2 and 3 a medium degree of variation, and little or no variation in types 4 and 5. Accordingly, we speak of types of high, medium, or low flexibility in creating figural patterns.

As described above, there are clear differences between the two student groups in terms of assignment to types and in terms of the occurrence of originality. With the exception of one student, all mathematically gifted students showed at least moderate flexibility or created at least one original figural pattern. However, for many students both were true. In the group $\mathrm{C}$, no original products occurred and all but one belong to the low flexibility types. It can thus be concluded that the two groups considered here differ in terms of mathematical creativity in creating figural patterns. In this context, it should be noted once again that the students in the comparison group are also high achievers in mathematics in terms of their performance in school.

In our view, there are essentially four possible explanations for the creativity-related differences between both groups. The first explains the differences by chance. This cannot be ruled out due to the small experimental group size, but it is unlikely due to the distinctness of the differences, so that we do not pursue this explanatory approach here.

Second, differences in inventing could be rooted in different knowledge and experience bases. It can be assumed that a certain base of domain-specific knowledge and experience is necessary to generate creative ideas in this domain (e.g., Silver, 1997). Regarding figural patterns, this could mean that experience and previously acquired knowledge in dealing with patterns and structures facilitates the development of one's own ideas for rule-based changes. This could be of particular importance when developing ideas for possible mathematical relationships starting from the given numbers 1 and 5. Thus, a greater wealth of knowledge and experience in the gifted students might have favored the variety of mathematical relations. However, while mathematical relations are an important dimension, they are only one of five dimensions of flexibility. Moreover, a necessary knowledge and experience base probably does not make the crucial difference in a group of high-achieving students. It can be assumed that all of them have a corresponding knowledge base, especially since no difficult mathematical relationships must be recognized or found when creating figural patterns. In addition, two rules about non-linear patterns and the square numbers were addressed and visualized in the introductory video. Thus, we assume that knowledge and experience differences are not causal of the observed differences.

It could also be hypothesized that the differences between both student groups are rooted in different abilities regarding generalizing patterns. Against this third explanation, however, speaks the mathematical simplicity of the given constraints (numbers 1 and 5). In their case study with 44 fourth graders, Fritzlar and Karpinski-Siebold (2012) found a strong relationship between students' mathematical achievement in the classroom and their ability to continue patterns or to generalize them. However, there were no differences between mathematically gifted and high achieving students regarding pattern generalizing although the used patterns were much more sophisticated. For this reason, too, it seems obvious that the ability to generalize patterns does not play a significant role in our study. Correspondingly the interview results show no correlations with the results of the growing pattern task in the entrance test, neither regarding flexibility nor related to originality. This lack of correspondences also suggests that the recognition and use of mathematical structures in determining numbers of elements in growing patterns entails different requirements, which can be assigned more to convergent thinking than to the creation of figural patterns.

In this context, however, it must be kept in mind that the entrance test comprised several tasks or subtasks on the recognition, memorization and use of mathematical structures (cf. Sect. 7.2). Although the individual results varied, all students identified as mathematically gifted were able to demonstrate particular abilities in mathematically challenging situations.

Following the remaining fourth approach, results suggest, that the special abilities of mathematically gifted primary school students in dealing with patterns and structures do not refer only to rather convergent thinking, but also to creative aspects. 
In previous sections we highlighted the distinction between mathematically gifted students and those who 'only' perform well to very well in regular mathematics classes. The process of selecting students participating in the study through teacher nomination followed by a giftedness test allows a comparison of these two groups. To our knowledge, this particularly meaningful methodological approach of group comparison is new for the primary school age. The results indicate that mathematically gifted primary students differ from high-achieving non-gifted students in their higher creativity in dealing with figural patterns and thus in the context of an important characteristic of mathematical giftedness. Although both groups are quite similar compared to the total group of all primary school students, the differences regarding creativity are very clear and impressive. Based on this result, it seems reasonable to assume that there is a strong correlation between mathematical giftedness and creativity in inventing mathematical patterns in primary school age. Of course, this may merely be relative creativity or "little c" (Leikin, 2009). This confirms the results of previous studies on the relationship between mathematical giftedness and creativity with older students (e.g., Leikin \& Lev, 2007; Lev \& Leikin, 2017) or other methodological approaches (e.g., Kattou et al., 2013; PittaPantazi et al., 2011). Results of the latter studies are even strengthened because the investigation of a large sample across the achievement spectrum used there facilitates the application of powerful statistical tools, but allows only uncertain conclusions for small subgroups such as high achieving or mathematically gifted students.

In summary, the consistency of the results of studies with different age groups and different methodological orientations impressively indicates the strength of the relationship between mathematical giftedness and (relative) mathematical creativity.

However, there is one boy (S9) identified as mathematically gifted in the group of students we studied who does not show any particular creativity. This may have various causes, about which we could only speculate at this point. In our opinion, it might nevertheless be worthwhile to investigate with larger groups of students whether different types of mathematical giftedness might also differ in terms of mathematical creativity. In addition, larger experimental groups would also further increase the certainty or significance of the results of the presented study.

The radar charts succeed in describing the variety of created figural patterns based on several criteria in such a way that comparisons regarding the flexibility and originality of pattern invention are easily possible. From our point of view, it seems worthwhile to explore whether this approach could also be suitable for other content areas where purely numerical comparisons and calculations of flexibility indices are not appropriate.
In addition to scientific results and methodological aids, consequences for teaching practice can also be derived from the study: experiences show that inventing figural patterns has potentials for creative mathematical activity for all primary school students. Furthermore, they indicate that efforts to foster mathematical creativity are also appropriate for high achieving students with good to very good results in mathematics classes. For a holistic fostering of abilities of mathematically gifted primary school students it seems to be necessary to look beyond logical and heuristic aspects to mathematical creativity.

Funding Open Access funding enabled and organized by Projekt DEAL.

Open Access This article is licensed under a Creative Commons Attribution 4.0 International License, which permits use, sharing, adaptation, distribution and reproduction in any medium or format, as long as you give appropriate credit to the original author(s) and the source, provide a link to the Creative Commons licence, and indicate if changes were made. The images or other third party material in this article are included in the article's Creative Commons licence, unless indicated otherwise in a credit line to the material. If material is not included in the article's Creative Commons licence and your intended use is not permitted by statutory regulation or exceeds the permitted use, you will need to obtain permission directly from the copyright holder. To view a copy of this licence, visit http://creativecommons.org/licenses/by/4.0/.

\section{References}

Akgul, S., \& Kahveci, N. G. (2016). A study on the development of a mathematics creativity scale. Eurasian Journal of Educational Research, 62, 57-76.

Aßmus, D. (2017). Mathematische Begabung im frühen Grundschulalter unter besonderer Berücksichtigung kognitiver Merkmale. Münster: WTM

Assmus, D. (2018). Characteristics of mathematical giftedness in early primary school age. In F. M. Singer (Ed.), Mathematical creativity and mathematical giftedness: Enhancing creative capacities in mathematically promising students (pp. 145-167). Springer.

Assmus, D., \& Fritzlar, T. (2018). Mathematical giftedness and creativity in primary grades. In F. M. Singer (Ed.), Mathematical creativity and mathematical giftedness: Enhancing creative capacities in mathematically promising students (pp. 55-81). Springer.

Bahar, A. K., \& Maker, C. J. (2011). Exploring the relationship between mathematical creativity and mathematical achievement. Asia-pacific Journal of Gifted and Talented Education, 3(1), 33-48.

Berlinger, N. (2015). Die Bedeutung des räumlichen Vorstellungsvermögens für mathematische Begabungen bei Grundschulkindern: Theoretische Grundlegung und empirische Untersuchungen. Münster: WTM

Carraher, D. W., Martinez, M. V., \& Schliemann, A. D. (2008). Early algebra and mathematical generalization. ZDM-The International Journal on Mathematics Education, 40(1) 3-22.

Devlin, K. (1994). Mathematics: The science of patterns. Scientific American Library. 
Fritzlar, T., \& Karpinski-Siebold, N. (2012). Continuing patterns as a component of algebraic thinking - an interview study with primary students. In ICME 12 Pre-proceedings (pp. 2022-2031)

Frobisher, L., \& Threlfall, J. (1999). Teaching and assessing patterns in number in the primary years. In A. Orton (Ed.), Pattern in the teaching and learning of mathematics (pp. 84-103). Cassell.

Fuchs, M. \& Käpnick, F. (2004). Mathe für kleine Asse. Empfehlungen zur Förderung mathematisch interessierter und begabter Kinder im 1. und 2. Schuljahr. Berlin: Cornelsen

Gajda, A., Karwowski, M., \& Beghetto, R. A. (2017). Creativity and academic achievement: A meta-analysis. Journal of Educational Psychology, 109(2), 269-299.

Haylock, D. (1997). Recognising mathematical creativity in schoolchildren. ZDM Mathematics Education, 29(3), 68-74.

Jauk, E., Benedek, M., Dunst, B., \& Neubauer, A. C. (2013). The relationship between intelligence and creativity: New support for the threshold hypothesis by means of empirical breakpoint detection. Intelligence, 41(4), 212-221.

Joklitschke, J., Baumanns, L., \& Rott, B. (2019). The intersection of problem posing and creativity: a review. In M. Nolte (Ed.), Including the highly gifted and creative students-current ideas and future directions: Proceedings of the 11th international conference on mathematical creativity and giftedness (MCG 11), 22.08.2019-24.08.2019, Universität Hamburg, Germany (pp. 59-67). Münster: WTM

Käpnick, F. (1998). Mathematisch begabte Kinder. Modelle, empirische Studien und Förderungsprojekte für das Grundschulalter. Frankfurt am Main: Lang Verlag

Kattou, M., Kontoyianni, K., Pitta-Pantazi, D., \& Christou, C. (2013). Connecting mathematical creativity to mathematical ability. ZDM-the International Journal on Mathematics Education, 45(2), $167-181$.

Kroesbergen, E. H., \& Schoevers, E. M. (2017). Creativity as predictor of mathematical abilities in fourth graders in addition to number sense and working memory. Journal of Numerical Cognition, 3(2), 417-440.

Krutetskii, V. A. (1976). The psychology of mathematical abilities in schoolchildren. Chicago: University of Chicago Press.

Kuckartz, U. (2014). Qualitative text analysis: A guide to methods, practice and using software. Sage Publications.

Leikin, R. (2009). Exploring mathematical creativity using multiple solution tasks. In R. Leikin, A. Berman, \& B. Koichu (Eds.), Creativity in mathematics and the education of gifted students (pp. 129-145). Sense Publishers.

Leikin, R., \& Lev, M. (2007). Multiple solution tasks as a magnifying glass for observation of mathematical creativity. In J. H. Woo, H. C. Lew, K. S. Park, \& D. Y. Seo (Eds.), Proceedings of the 31st international conference for the psychology of mathematics education (Vol. 3, pp. 161-168). The Korea Society of Educational Studies in Mathematics.

Leikin, R., \& Pitta-Pantazi, D. (2013). Creativity and mathematics education: The state of the art. ZDM-the International Journal on Mathematics Education, 45(2), 159-166.

Lev, M., \& Leikin, R. (2017). The interplay between excellence in school mathematics and general giftedness: Focusing on mathematical creativity. In R. Leikin \& B. Sriraman (Eds.), Creativity and giftedness: Interdisciplinary perspectives from mathematics and beyond (pp. 225-238). Springer.

Lubart, T. (2016). Creativity and convergent thinking: Reflections, connections and practical considerations. RUDN Journal of Psychology and Pedagogics, 4, 7-15.

Lüken, M. M., Peter-Koop, A., \& Kollhoff, S. (2014). Influence of early repeating patterning ability on school mathematics learning. In P. Liljedahl, S. Oesterle, C. Nicol, \& D. Allan (Eds.), Proceedings of the Joint Meeting of PME 38 and PME-NA 36 (Vol. 4, pp. 137-144). PME.
Mayring, P. (2014). Qualitative content analysis: theoretical foundation, basic procedures and software solution. Retrieved from http://nbn-resolving.de/urn:nbn:de:0168-ssoar-395173. Accessed 15 Dec 2021

Miller, J., \& Warren, E. (2012). An exploration into growing patterns with young Australian indigenous students. In J. Dindyal, L. P. Cheng, \& S. F. Ng (Eds.), Mathematics education: Expanding horizons. MERGA: Singapore.

Nolte, M., \& Pamperien, K. (2017). Challenging problems in a regular classroom setting and in a special foster programme. ZDMMathematics Education, 49(1), 121-136.

Pitta-Pantazi, D., Constantinos, C., Kontoyianni, K., \& Kattou, M. (2011). A model of mathematical giftedness: Integrating natural, creative, and mathematical abilities. Canadian Journal of Science, Mathematics and Technology Education, 11(1), 39-54.

Radford, L. (2006). Algebraic thinking and the generalization of patterns: a semiotic perspective. In S. Alatorre, J. L. Cortina, M. Sáiz, $\&$ A. Méndez (Eds.), Proceedings of the 28th annual meeting of the North American Chapter of the International Group for the Psychology of Mathematics Education (Vol. 1, pp. 2-21). Universidad Pedagógica Nacional.

Rivera, F. D. (2018). Pattern generalization processing of elementary students: Cognitive factors affecting the development of exact mathematical structures. EURASIA Journal of Mathematics, Science and Technology Education, 14(9), 31.

Rivera, F. D. (2010a). Visual templates in pattern generalization activity. Educational Studies in Mathematics, 73, 297-328.

Rivera, F. D. (2010b). Second grade students' preinstructional competence in pattern activity. In M. F. Pinto \& T. Kawasaki (Eds.), Proceedings of the 34th conference of the International Group for the Psychology of Mathematics Education (Vol. 4, pp. 81-88). PME: Tokyo.

Rivera, F. (2013). Teaching and learning patterns in school mathematics: Psychological and pedagogical considerations. Springer.

Rivera, F. D., \& Becker, J. R. (2016). Middle school students' patterning performance on semi-free generalization tasks. The Journal of Mathematical Behavior, 43, 53-69.

Schoevers, E. E., Kroesbergen, E. H., \& Kattou, M. (2018). Mathematical creativity: A combination of domain-general creative and domain-specific mathematical skill. The Journal of Creative Behavior, 54(2), 242-252.

Sheffield, L. J. (2003). Extending the challenge in mathematics. Developing mathematical promise in $K-8$. Thousands Oaks: Corvin Press.

Shen, Y., \& Edwards, C. P. (2017). Mathematical creativity for the youngest school children: Kindergarten to third grade teachers' interpretations of what it is and how to promote it. The Mathematical Enthusiast, 14(1), 325-346.

Silver, E. A. (1997). Fostering creativity through instruction rich in mathematical problem solving and problem posing. ZDM Mathematics Education, 29(3), 75-80.

Singer, F. M., Pelczer, I., \& Voica, C. (2011). Problem posing and modification as a criterion of mathematical creativity. In M. Pytlak, E. Swoboda, \& T. Rowland (Eds.), CERME 7-Proceedings of the seventh congress of the European Society for Research in Mathematics Education (pp. 1133-1142). Rzeszów.

Sriraman, B. (2005). Are giftedness and creativity synonyms in mathematics? The Journal of Secondary Gifted Education, 17(1), 20-36.

Stacey, K. (1989). Finding and using patterns in linear generalising problems. Educational Studies in Mathematics, 20, 147-164.

Sternberg, R. J., \& O'Hara, L. A. (1999). Creativity and intelligence. In R. J. Sternberg (Ed.), Handbook of creativity (pp. 251-272). Cambridge University Press. 
Thurstone, L. L. (1950). Some primary abilities in visual thinking. Proceedings of the American Philosophical Society, 94(6), 517-521.

Vale, I., Pimentel, T., Cabrita, I., \& Barbosa, A. (2012). Pattern problem solving tasks as mean to foster creativity in mathematics. In T. Y. Tso (Ed.), Proceedings of the 36th conference of the International Group for the Psychology of Mathematics Education (Vol. 4, pp. 171-178). PME.

Warren, E. (2005). Young children's ability to generalise the pattern rule for growing patterns. In H. L. Chick \& J. L. Vincent (Eds.), Proceedings of the 29th conference of the International Group for the Psychology of Mathematics Education (Vol. 4, pp. 305-312). PME.

Warren, E., \& Cooper, T. (2008). Generalising the pattern rule for visual growth patterns: Actions that support 8 year olds' thinking. Educational Studies in Mathematics, 67(2), 171-185.

Wieczerkowski, W., Cropley, A. J., \& Prado, T. M. (2000). Nurturing talents/gifts in mathematics. In K. A. Heller, F. J. Mönks, R. J. Sternberg, \& R. F. Subotnik (Eds.), International handbook of giftedness and talent (2nd ed., pp. 413-425). Elsevier.

Wilkie, K. J. (2019). Investigating secondary students' generalization, graphing, and construction of figural patterns for making sense of quadratic functions. Journal of Mathematical Behavior, 54.
Wilkie, K. J. (2021). Seeing quadratics in a new light: Secondary mathematics pre-service teachers' creation of figural growing patterns. Educational Studies in Mathematics, 106, 91-116.

Yuan, X., \& Sriraman, B. (2011). An exploratory study of relationsships between students' creativity and mathematical problemposing abilities. In B. Sriraman \& K. H. Lee (Eds.), The Elements of creativity and giftedness in mathematics (pp. 5-28). Sense Publishers.

Zazkis, R., \& Liljedahl, P. (2002). Generalization of patterns: The tension between algebraic thinking and algebraic notation. Educational Studies in Mathematics, 49, 379-402.

Publisher's Note Springer Nature remains neutral with regard to jurisdictional claims in published maps and institutional affiliations. 